\title{
Conjoint Statement of the SNM and the ACNP on Credentialing and Delineation of Privileges for Cardiovascular CT
}

\section{GENERAL}

A. The Joint Commission on Accreditation of Hospitals requires that a system be in place for delineating privileges for every hospital staff member. The Joint Commission on Accreditation of Hospitals does not, however, spell out specific qualifications for any given privilege or level of privilege. Privileges are generally hospital-specific and are not usually transferable from hospital to hospital.

B. The granting of clinical privileges cannot and should not depend on only a single criterion, such as board certification or membership in a particular specialty society. Other options should be available, such as privileges based on documented evidence of training, experience, judgment, and demonstrated current competence.

C. It is the final responsibility of the hospital medical staff and hospital governing board to ensure that a physician meets a reasonable standard of competency.

D. SNM has reviewed the current guidelines from other specialty societies and endorses the following credentialing recommendations.

\section{CARDIOVASCULAR CT (CCT)}

Based on recommendations of a task force on clinical competence and training from the American College of Cardiology Foundation/American Heart Association/ American College of Physicians ( $\mathrm{A}$ Am Coll Cardiol. 2005; 46:383-402 for physicians in practice and $J$ Am Coll Cardiol. 2006;47:893-920 for physicians in training), the SNM believes that physicians certified by the American Board of Nuclear Medicine should be granted privileges to independently perform and interpret CCT if they meet all the following training criteria (Physicians with certification in specialties other than nuclear medicine should meet the requirements for CCT set by their major professional society, such as is described in the ACCF/AHA Clinical Competence Statement on Cardiac Imaging with CT and Magnetic Resonance [J Am Coll Cardiol. 2005;46:383402].):

A. The physician must interpret $150 \mathrm{CCT}$ studies with intravenous contrast material under the supervision

COPYRIGHT $\odot 2007$ by the Society of Nuclear Medicine, Inc.

DOI: 10.2967/jnumed.107.041285 of a qualified physician. For 35 of these studies, the physician being trained must be present and involved in their acquisition.

B. The physician must complete 2 mo of training in CCT (a minimum of $35 \mathrm{~h} / \mathrm{wk}$, of which 4 wk must represent supervised laboratory time). The remaining $140 \mathrm{~h}$ can include Web-based CT education, CD/ DVD training, attendance at major medical meetings, or other relevant training activities. The 2-mo requirement does not need to be continuous. One hundred CME hours in CT may be applied to nonsupervised laboratory time and can concurrently be applied to the CT training requirement for interpretation of SPECT/ CT or PET/CT.

C. To provide evidence of continuing competence, physicians need to participate in maintenance of certification as required by the specialty board. There needs to be evidence of continuing competence in the interpretation and reporting of 50 CCT examinations per year.

\section{GENERAL PROCEDURES FOR CREDENTIALING PROCESS}

A. It is recommended that any physician applying for privileges to practice nuclear medicine in either a hospital or clinical setting document proper credentials. Credentialing (licensure and certification) is considered one of the minimum standards for the delineation of privileges to practice nuclear medicine. The format in Part B below is recommended as a method of delineating such privileges.

B. It is recommended that, in delineating privileges to practice nuclear medicine and CCT for an individual physician, the following criteria should be considered:

1. Graduation from a Liaison Committee on Medical Education-approved medical school or school of osteopathy or graduation from a foreign medical school with possession of an Educational Commission for Foreign Medical Graduates certificate score acceptable for medical licensure in the state of medical practice. Training in an Accreditation Council for Graduate Medical Education (ACGME)-approved residency program in nuclear medicine or the equivalent should also be considered. 
Training equivalent to that provided in ACGMEapproved programs should be ascertained by referral to the appropriate American Board of Medical Specialties (ABMS)-recognized board.

2. Clinical competence, appropriate for medical practice. Malpractice insurance may be required. At present, current competency may be demonstrated by one of the following:

a. Documentation that the physician has been tested and issued a certificate by the appropriate ABMS-recognized specialty board, or evidence of recertification as required by the particular certifying organization.

b. Maintenance of certification as required by the appropriate ABMS-recognized specialty board.

3. A method of review for regular delineation of privileges as required by individual institutions annually.
4. Definition of which individual procedure or category of procedures may be performed by each physician.

\section{APPROVAL}

This credentialing statement was approved by the board of directors of the SNM on September 10, 2006, and the board of directors of the American College of Nuclear Physicians (ACNP) on September 21, 2006.

\section{SNM PRACTICE STANDARD COMMITTEE}

Dominique Delbeke, Leonie L. Gordon (Chair of SNM Practice Standard Committee), George M. Segall, Mark Travin (SNM Cardiovascular Council), Albert J. Sinusas (SNM Cardiovascular Council), Peter S. Conti, Henry D. Royal, Michael M. Graham, Helena R. Balon, Gary Dillehay, Alexander J. McEwan, Kevin J. Donohoe, Michael L. Middleton, and Martin P. Sandler. 